\title{
Application of the Motion Control System for Mine Rescue Robots
}

\author{
Shitao $\mathrm{Wu}^{*}$
}

Shandong University of Science and Technology, Taian, Sahndong, China

\begin{abstract}
The solution of motion control system is proposed, researched and developed according to six-pedrail mine rescue robot. According to different motion types, motion analysis of main drive module and arm drive module is analyzed individually. The method of modular design is used by hardware part and soft part of motion control system of mine rescue robot. Hardware part includes host computer module, main drive module and arm drive module. The Hall sensors are used by position control or velocity control of main drive module and arm drive module. The soft part includes host computer module program, main drive module program and arm drive module program. A series of experiments of motion control system of mine rescue robot is done, and data of experiments is analyzed in the end. The research shows that motion control system developed meets the requirements of mine rescue robot because of good precision and real-time.
\end{abstract}

Keywords: Mine rescue robot, Motion control system, Module, Pulse.

\section{INTRODUCTION}

In recent 10 years, the developed countries such as Japan, and the United States have done a lot of work in the study of rescue robots for earthquake, fire and other disasters and work out various rescue robots which can be used for disaster scene. After the rescue work of the "911" event of the New York world trade center in 2001, according to the report of the Times, robots found 10 bodies in narrow or dangerous areas where the rescue dogs can't arrive in the first 10 days of rescue. The number of bodies that was found by rescue robots is basically the same with that of rescue persons, but the spent time is less than half the time of rescue workers at the scene [1]. There are totally six crawlers in mine rescue robot, two of them are main tracks, four of them are swing arm crawler modules, they are all directly related to the operation of the rescue robot. But different movement forms of crawlers are different, the main crawlers need two driving wheels to coordinate movement, to be able to go straight and turn; and the four movements of track swing arms are relatively independent. Therefore, main drive and swing arm drive are needed for kinematic analysis respectively.

\section{CHARACTERISTICS OF NEW ROBOT CON- TROLLER}

Modularity is a modern method of modular system design and establishment. According to the modular design method, the system is composed of a variety of functional modules, each of which is complete and individual. System set up in such way, does not only has good performance, short development cycle, but also has lower cost. Modular also makes the system open-ended, easy to be modified,

\footnotetext{
*Address correspondence to this author at the Shandong University of Science and Technology, Taian, Sahndong, China; Tel: 13695388777 ; E-mail: Wust26789@163.com
}

refactored and added configuration functions. New type of robot controller should have the following features:

1) Open-ended system structure. When adopting the structure of open-ended software and hardware, the function can be easily extended according to the requirement to make it applicable to different types of robots or robot automatic production lines.

2) The reasonable modular design. According to the system requirements and electrical characteristics for hardware, designing as to the modular, it is not only convenient to install and maintain, but also improving the reliability of the system; the system structure is more compact.

3) Effective task partitioning. Different subtasks are implemented by different function modules, for the sake of modifying, addition, configuring function.

4) Multi task real-time requirements. The robot controller must be able to complete processing of external interrupt in a certain time, and can make multiple tasks working simultaneously.

5) Network communication function. Take the advantages of the network communication function, so that to realize resources sharing or cooperative work of multiple robots.

With the development of robot technology, the expansion of the robot application field, higher requirements on the performance of the robot have been put forward. Therefore, how to apply the research results of other areas (such as image processing, voice recognition, optimal control, artificial intelligence, etc.) on the real-time operation of the robot control system effectively is a challenging research work. And developing standard, modular robot control system of openended architecture is of great significance to improving the 
performance and independent ability of robots, and promoting the development of robot technology [2].

\section{KINEMATICS ANALYSIS OF MINE RESCUE RO- BOT}

Kinematics analysis of mobile robot is the basis of motion control, establishing kinematics equation of mine rescue robot and having kinematics analysis is of great significance on searching its kinematics characteristics, optimizing motion control parameters, and determining the motion control system.

\subsection{Motion Control System of Mine Rescue Robot}

Motion control system of mine rescue robot is the base to realize the information collection and transmission underground. It consists of the upper computer module, the main driver module and the swing arm drive module, among which the main driver module and the swing arm driver module are movement executors.

The main drive module is controlled by two independent motors to achieve differential controls, to realize the forward, backward and turning of robot; there are a total of four swing arms in swing arm driver module, which are driven by four independent motors, to control their swing arm gestures, assist robot to climb, go through obstacle and across the ditch, see Table 1.

\subsection{Kinematics Equation of Mine Rescue Robot Main Drive Module}

\subsubsection{WMRII Kinematics Equation}

Systems are actually often subjected to certain constraints, thus they are also called as the limited system. There are two kinds of constraint conditions, holonomic constraint and nonholonomic constraint, and these integrated constraints can always be eliminated through calculation from the kinematics equation [3]. A dimension reduction kinematics equations will be obtained, which is quite favorable for the analysis and design of motion control system. And because the nonholonomic constraint is not integrable, we can't get the similar dimension reduction effect, even if special method is used to eliminate its representative item from the system, dynamics equation can also increase the degree of nonlinear and mutual coupling of variable movement control system. Although constraints and kinematic equation can be used to express the system state to control and design at the same time, yet it will increase the complexity of motion control and design. Nonholonomic constraints are usually the constraints on the system velocity, which is not integrable constraint and can't be integrally translated into space location constraints [4].

\section{THE HARDWARE DESIGN OF MOTION CON- TROL SYSTEM OF MINE RESCUE ROBOT}

\subsection{The Whole Design of Motion System Design of Mine Rescue Robot}

The module design is adopted based on the design of motion system of mine rescue robot. It consists of three parts, upper monitor, main driver unit and swing arm drive module unit.

The brushless DC motor is a new kind of DC motor emerged with the development of electronic technology, which is an important motion part of industry equipment. In recent years, brushless DC motor has been widely used as middle power mixture-speed motor with high performance in the industry as the cost of rare performance earth material and electronic devices is constantly increasing [5].

Because of the shown advantages, brushless DC motor is chosen as the drive motor for mine rescue robot. There are a total of six brushless DC motors that are needed by mine rescue robot, including two main drive motors and four swing arms drive motors. They are all chosen from domestic manufacturer, and their main parameters are as follows:

1) The rated speed is $4000 \mathrm{RPM}$, and the reduction ratio is $1 / 18$.

2) The rated voltage is $24 \mathrm{~V}$, the rated power is $150 /$ $105 \mathrm{~W}$, and the rated torque is $0.42 \mathrm{~N} \cdot \mathrm{M} / 0.3 \mathrm{~N} \cdot \mathrm{M}$, the peak torque is $1 \mathrm{~N} \cdot \mathrm{M} / 0.7 \mathrm{~N} \cdot \mathrm{M}$.

3) Operating environmental temperature is $20^{\circ} \mathrm{C} \sim 60^{\circ} \mathrm{C}$.

4) The position sensors are the hall sensor, the power angle of which is $120^{\circ}$.

The assorted driver of brushless DC motor adopts special high performance brushless motor control chip, which is suitable for three-phase brushless DC motor drive. The driver has the characteristics such as PWM step-less speed regulation, closed-loop control, optional 60/120 electric angle, pros/cons turn, start/stop of the motor, automatic current

Table 1. The advantages of brushless DC motor.

\begin{tabular}{|c|c|c|c|c|c|c|c|c|c|c|c|}
\hline $\begin{array}{l}\text { Performance } \\
\text { System }\end{array}$ & $\begin{array}{l}\text { Mechanical } \\
\text { characteristic }\end{array}$ & $\begin{array}{l}\text { Overload } \\
\text { capacity }\end{array}$ & $\begin{array}{c}\text { Controlla- } \\
\text { bility }\end{array}$ & $\begin{array}{l}\text { Station- } \\
\text { arity }\end{array}$ & Noise & $\begin{array}{l}\text { Electromag- } \\
\text { netic inter- } \\
\text { ference }\end{array}$ & $\begin{array}{l}\text { Maintaina- } \\
\text { bility }\end{array}$ & Life & Volume & Efficiency & Cost \\
\hline $\begin{array}{c}\text { AC Asynchro- } \\
\text { nous Motor }\end{array}$ & Soft & Small & Difficult & Poor & Larger & Small & Easy & Long & Big & Low & Low \\
\hline $\begin{array}{l}\text { Brushless DC } \\
\text { Motor }\end{array}$ & Hard & Big & Easy & Good & Big & Serious & Difficult & Short & Small & High & High \\
\hline $\begin{array}{c}\text { Brushless DC } \\
\text { Motor }\end{array}$ & Hard & Big & Easy & Good & Small & Small & Easy & Long & Small & High & High \\
\hline
\end{tabular}


limit, with the electric brakes, and overheating protection. It can provide other systems with a $5 \mathrm{~V} / 200 \mathrm{~mA}$ regulated DC power supply. The main parameters are as follows:

1) Supply voltage: DC $12 \mathrm{~V}-48 \mathrm{~V}$ (general $24 \mathrm{~V}-36$ adaptive).

2) DC: 0-8A (automatic limit on current when it reaches the maximum current).

3) Rated power: $120 \mathrm{~W}$.

4) Environmental temperature: $-30{ }^{\circ} \mathrm{C}$ to $75^{\circ} \mathrm{C}$.

5) Insulation resistance: $>50 \mathrm{M} \Omega$.

The relation between the voltage on SP port and the speed of motor drive is shown in Table 2.

Table 2. Voltage-speed.

\begin{tabular}{|l|c|c|c|c|c|}
\hline Voltage (V) & 2.5 & 3.0 & 3.5 & 4.0 & 4.5 \\
\hline Speed (r/s) & 30 & 75 & 114 & 151 & 190 \\
\hline
\end{tabular}

Least square method is linearly fitted on the data of Table 2 to get linear Formula (1):

$y=79.2 x-165.2$

Among it, $\mathrm{y}$ is for speed, $\mathrm{x}$ is for the voltage. This formula is the basic formula for speed adjustment, but it is important to notice the application range. The formula can be continuously transformed into the relationship of the drive voltage and pulse number per unit time:

$z=\frac{2 \times 18 y}{60}=0.6 y$

\subsection{Main Drive Module of Mine Rescue Robot}

The main drive module of mine rescue robot refers to the operation control of the two main motors, to make the mine rescue robot move forward, backward, stop and turn. Main drive control module is completed by the coordination of upper computer and lower computer, and then they are turned into a machine instructions that can be recognized according to the master program of instruction, and analysis of the data returned from lower computer. Main task of lower computer is to accept the instructions from upper computer, and monitor the motor running state, then adjust the speed of the motor, and return the monitoring data to the upper computer.

\subsection{Swing Arm Driver Module}

Mine rescue robots have four swing arms, which are mainly used to control the robot pose. Mine rescue robots can cross obstacle, climb and cross smooth ditch [6], which have very important meaning on the smooth running of mine rescue robot under unstructured environment. The swing arm control module of mine rescue robot includes PC, MAX232,
STC89C52, brushless DC motors and drives and fourchannel voltage comparator LM339.

\section{THE DESIGN OF SOFTWARE OF MOTION CON- TROL SYSTEM}

The motion control software structure of mine rescue robot is also based on modular design, which is divided into upper computer module, main driver module and swing arm driver module, of which the upper desktop module is based on general PC, and takes Windows XP as the operation platform, using $\mathrm{VC}++$ as software development. The main driver module and the swing arm driver module takes STC89C52 single-chip microcomputer as the core, to receive instructions from the upper computer, to control the state of related devices, and to return the feedback information to provide the reference for the upper machine [7]

$\mathrm{VC}++$ is the programming software introduced by $\mathrm{Mi}-$ crosoft, which is the highest comprehensive and the most powerful high-end software development tool that involves a concentration of editing, compiling, connection, debugging and running. The development environment of $\mathrm{VC}++$ has inherited the high efficiency, flexible pointer application, rigorous encapsulation of data and structures of these advantages etc. from $\mathrm{C}$ and $\mathrm{C}++$ language. It also provides a convenient and practical interactive visual programming environment. Right now, it has an extensive application. The upper computer uses $\mathrm{VC}++$ as the software development platform to establish upper computer software.

\section{INTERGRATED DEBUGGING ON MOTION CON- TROL SYSTEM OF MINE ROBOT}

The integrated debugging on motion control system is the execution system of mine rescue robot; main drive module and swing arm drive module achieve different actions according to the order of upper computer. As to main drive module, the main actions are: going straight and turning, and as to swing arm module, the main action is the rotation of swing arm [8].

\subsection{Main Drive Module}

\subsubsection{Straight Going}

There are two main motors for the main drive module of mine rescue robot, which are differential motion, if the voltages added on the SP port of drivers, are the same, the rotating speed of two motors should be completely the same, and the motion trail of robot should be a line. As to the system in this paper, the speed is $0.2 \mathrm{~m} / \mathrm{s}$ (the speed here is the speed of the geometric center of robot), the experimental data of different moving length Figs. (1 and 2):

The calculation formula of average discrepancy of straight going:

$\Delta d=\frac{\sum_{i=1}^{n}\left|x_{i}-x_{t i}\right|}{n}=\frac{\sum_{i=1}^{n}\left|d_{i}\right|}{n}$ 
Table 3. Experiment data of straight movement distance of main drive module.

\begin{tabular}{|c|c|c|c|c|c|}
\hline Serial number Project & 1 & 2 & 3 & 4 & 5 \\
\hline Designed Distance & 0.50 & 1.00 & 1.50 & 2.00 & 2.50 \\
\hline The Actual Distance & 0.51 & 1.02 & 1.52 & 2.01 & 2.51 \\
\hline Absolute Error & 0.01 & 0.02 & 0.02 & 0.01 & 0.01 \\
\hline The Relative Error & $2 \%$ & $2 \%$ & $1.3 \%$ & $0.5 \%$ & $0.4 \%$ \\
\hline
\end{tabular}

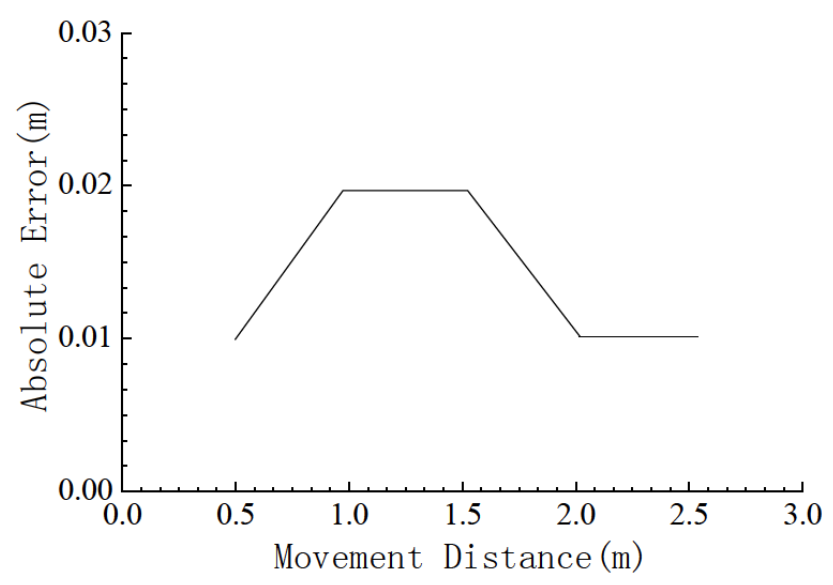

Fig. (1). Absolute error of main motor movement.

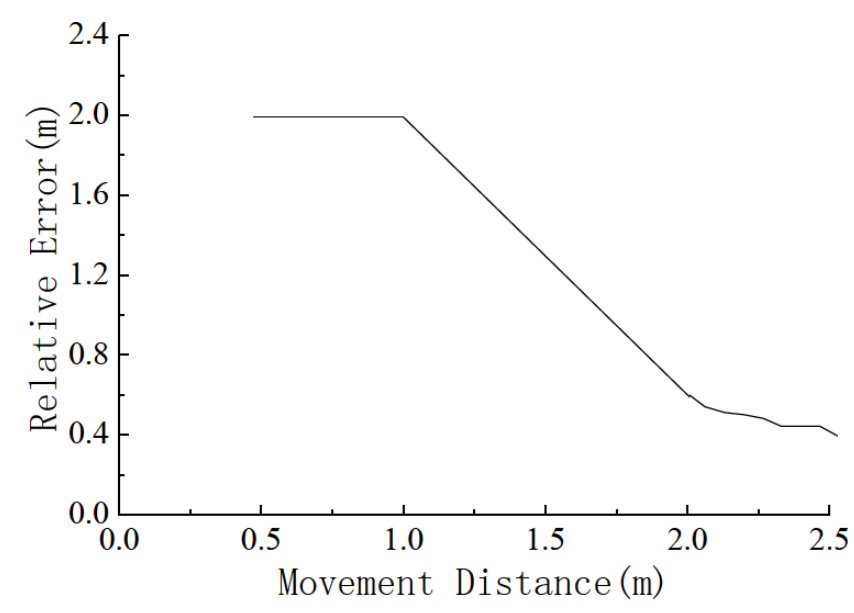

Fig. (2). Relative error of main motor movement.

The calculation formula of sample standard error:

$\sigma=\sqrt{\frac{\sum_{i=1}^{n}(\mathrm{xi}-\bar{x})^{2}}{n-1}}=\sqrt{\frac{\sum_{i=1}^{n} d_{i}^{2}}{n-1}}$ Eq. (4)

According to Table 3 and Formulas (3) and (4), the arithmetic average error of the main drive module of control system of mine rescue robot when going straight can be obtained: $\Delta \mathrm{d}=0.014 \mathrm{~m}$, simple standard average error is $\sigma=0.0055 \mathrm{~m}$.

\subsubsection{Turn}

When turning is relative to the geometric center of the robot, and the speed of the two main driving wheels of mine rescue robots are at obtained the different times, the radius and angle of mine rescue robot driver module will turn. At the same time, we can know that singularity exists in the radius of the mine rescue robot when turning. In order to be convenient for analysis, the speeds of two main drive wheels are $0.2 \mathrm{~m} / \mathrm{s}$ and $0.1 \mathrm{~m} / \mathrm{s}$ respectively, $\theta=180^{\circ}$, that is $\mathrm{r}=3 \mathrm{~d}=$ $0.732 \mathrm{~m}$ or $\mathrm{r}=-0.3 \mathrm{~d}=732 \mathrm{~m}$ (the direction of counterclockwise rotation is negative), the trajectory of robot is semicircle, the experimental data is shown in Table 4.

According to Table 4 and Formulas (3) and (4), the arithmetic average error of turning can be obtained: $\Delta \mathrm{d}=0.019 \mathrm{~m}$, simple standard average error is $\sigma=0.0052 \mathrm{~m}$.

\subsection{Swing Arm Driver Module}

The main actions of mine rescue robot arm driver module are the four rotary motions of the swing arm and independent controller respectively. When mine rescue robot is climbing, the swing arm posture should be adjusted to complete actions such as obstacle, ditch or channel crossing. Now take the angular velocity $\omega=\pi / 12$ (s) to carry out swing arm rotation experiment. The experimental data is given in the Table 5 [9].

According to Table 5 and formulas (3) and (4), the arithmetic average error of turning is $\Delta \mathrm{d}=0.88^{\circ}$, sample standard error is $=0.16^{\circ}$ Figs. $(3$ and 4$)$.

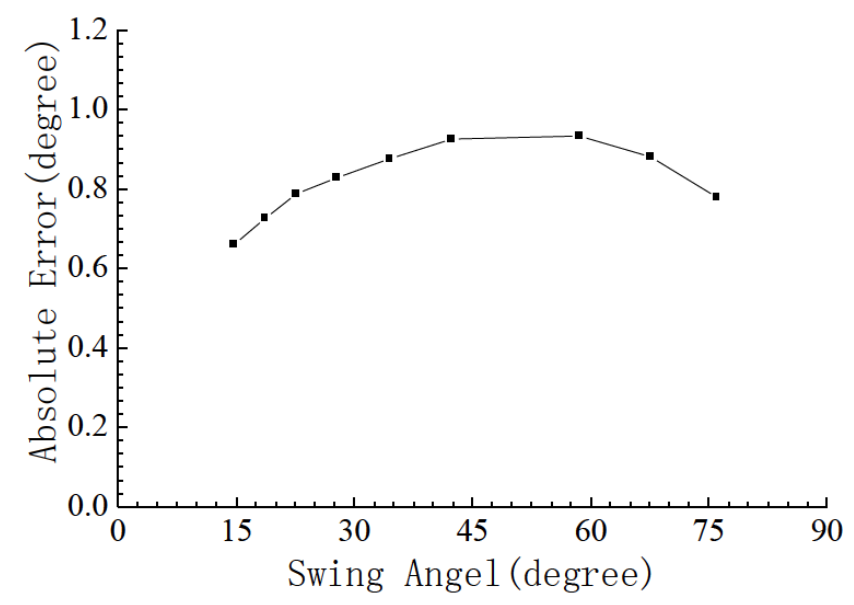

Fig. (3). Absolute error of swing movement. 
Table 4. Experiment data of turning movement of main drive motor $(\mathrm{m})$.

\begin{tabular}{|c|c|c|c|c|}
\hline Direction Project & Forward Clockwise & Forward Anti-clockwise & Fall back Clockwise & Fall back Anti-clockwise \\
\hline \hline The Measured Radius & 0.755 & 0.750 & 0.753 & 0.748 \\
\hline Absolute Error & 0.023 & 0.018 & 0.020 & 0.016 \\
\hline The Relative Error & $3.1 \%$ & $2.5 \%$ & $2.7 \%$ & $2.2 \%$ \\
\hline
\end{tabular}

Table 5. Experiment data of swing turning angle $\left({ }^{\circ}\right)$.

\begin{tabular}{|c|c|c|c|c|c|}
\hline Serial number Project & 1 & 2 & 3 & 4 & 5 \\
\hline Designed Angle & 15.0 & 30.0 & 45.0 & 60.0 & 75.0 \\
\hline The Actual Distance & 15.7 & 30.9 & 46.0 & 61.0 & 75.8 \\
\hline Absolute Error & 0.7 & 0.9 & 1.0 & 1.0 & 0.8 \\
\hline The Relative Error & $4.1 \%$ & $3 \%$ & $2.2 \%$ & $1.7 \%$ & $1.1 \%$ \\
\hline
\end{tabular}

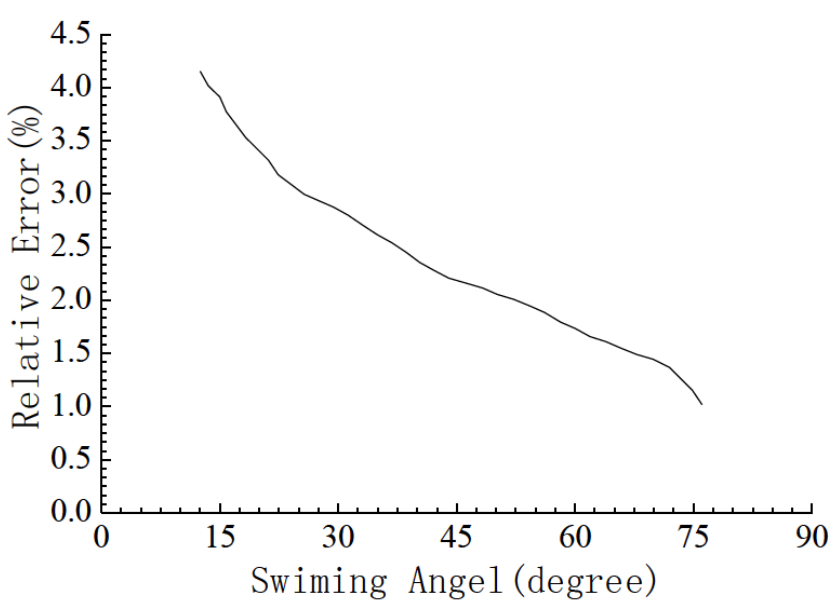

Fig. (4). Relative error of main motor movement.

\subsection{Error Analysis}

According to its nature or reasons, errors can be divided into random/chance error, systematic error and mistake error. Random error refers to error changing with unpredictable principles under certain experimental conditions, and the error of experiments value is changeable [10].

System errors are generated by a lot of factors. These are mainly the following several aspects:

1) First is the error formed during the production process and assembly process of robot parts, such as different sizes of four robot wheels.

2) The imbalance of robot load, geometric center and gravity center is not on the same line; which is also an important source of the systematic errors.

3) Measuring method and measuring instruments are the cause of system error.

There are also lots of reasons that cause random error, including the following several aspects:
1) The speed of the main drive motor is controlled by the voltage provided by the digital potentiometer, and the location of the digital potentiometer tap is permanent. when the $\mathrm{PC}$ is carrying on processing, quantization error exists, which is the main source of the random error.

2) The sliding and vibration of robot are also the source of error.

3) The random error also has certain relations with the tightness of the robot's track.

\section{CONCLUSION}

This article mainly studies on the motion control system of mine rescue robot with six tracks. The kinematics equation of motion control system of mine rescue robot was established, the system software and hardware were developed through the kinematic analysis, and the system scheme is verified through a series of experiments. The designed motion control system of mine rescue robot in this paper has brought out the effective control of the rescue robot, and it has met the basic needs in complex environments on realtime, reliability, easy maintenance and the control precision.

\section{CONFLICT OF INTEREST}

The author confirms that this article content has no conflict of interest.

\section{ACKNOWLEDGEMENTS}

Declared none.

\section{REFERENCES}

[1] Z. Wang, "Research status and development trend of disaster rescue robot," Journal of Modern Electronic Technology, vol. 256, no.17, pp. 152-155, 2007.

[2] W. Zhao, "Research and Design of Modular Robot Motion Control System," Dissertation, Wuhan Science and Technology University, Wuhan, 2008. 
[3] R. R. Siegwart, and I.R. Nobucks, Autonomous Mobile Robot Introduction, Xi 'an Jiaotong University Press: Xi 'an, 2006.

[4] Y. Hu, Theory and Application of Linear Control Systems. National Defence Industry Press: Beijing, 2005.

[5] L. G. GongJun, "Application and development of brushless DC motor in the industrial," Micro \& Special Motor, vol. 28, no.5, pp. $15-19,2000$

[6] J. Wei, G. Jia, and H. Ma, "Virtual prototype simulation analysis on mine rescue robot," Mechanical Science And Technology, vol. 27, no.11, pp. 1370-1373, 2008.
[7] G. Dudek, and M. Jenkin, Computational Principles of Mobile Robotics, Cambridge University Press: London, 2000.

[8] J. W. S. Martell, and G. Gini, "Robotic hands: design review and proposal of new design process," Engineering and Technology, vol. 20, pp. 85-90, 2007.

[9] Y. Nakamura, Advanced Robotics, Redundancy and Optimization, Addison-Wesley Publishing Company: New York, 1991.

[10] D. N. Nenchev, "Redundancy resolution through local optimization," Journal of Robotic Systems, vol. 6, no. 6, pp. 7692-798, 1989 .

Received on: May 26, 2015

Revised on: July 14, 2015

Accepted on: August 10, 2015

(C) Shitao Wu; Licensee Bentham Open.

This is an open access article licensed under the terms of the (https://creativecommons.org/licenses/by/4.0/legalcode), which permits unrestricted, non-commercial use, distribution and reproduction in any medium, provided the work is properly cited. 